\title{
Effect of L-threo-3,4-Dihydroxyphenylserine (L-DOPS), an Immediate Precursor of Norepinephrine, on the Cerebral Blood Flow in Rats
}

\author{
Etsuro SATO, Tsunemasa IRIE and Junki KATSUBE \\ Research Laboratories, Sumitomo Pharmaceuticals Co., Ltd., \\ 1-98. Kasugadenaka 3-chome, Konohana-ku, Osaka 554, Japan
}

Accepted November 8, 1986

\begin{abstract}
L-threo-3,4-Dihydroxyphenylserine ( $L$-DOPS), a norepinephrine (NE) precursor, $3 \mathrm{mg} / \mathrm{kg}$. i.v., increased the cerebral blood flow (CBF) in both the striatum and hippocampus as well as the mean arterial blood pressure (MABP) in urethane-anesthetized rats, as NE infusion did. The L-DOPS induced increase in CBF was inhibited by benserazide ( $3 \mathrm{mg} / \mathrm{kg} / \mathrm{hour}$ ), a peripheral aromatic L-amino acid decarboxylase inhibitor, and propranolol ( $3 \mathrm{mg} / \mathrm{kg}$. i.p.), a $\beta$-adrenoceptor blocker as well. These results suggest that the effects of L-DOPS may be attributed to the action of NE formed from L-DOPS, and the action may be mediated by stimulation of $\beta$-adrenoceptor.
\end{abstract}

A synthetic amino acid, L-threo-3.4dihydroxyphenylserine (L-DOPS) has been known to be decarboxylated by aromatic Lamino acid decarboxylase to yield norepinephrine (NE) in vitro (1) and in vivo (2-4). It has also been reported that L-DOPS produced a positive chronotropic effect in rat atrial preparations (5) as well as an inotropic effect in open-chest rats (6), a slow onset and long-lasting hypertensive effect in rats (7) and a diuretic effect in rats and mice (8). In clinical studies, DL- or LDOPS has recently been reported to improve postual hypotension and dizziness in parkinsonian patients (9), and the patients with familial amyloid polyneuropathy (10) or ShyDrager syndrome (11), and also to show beneficial effect on akinesia or freezing phenomenon in advanced parkinsonian patients (12). In the present study, the effect of L-DOPS on the cerebral blood flow (CBF) was studied in rats in comparison with that of NE.

The experiments were carried out in male Sprague-Dawley rats weighing between 240 and $310 \mathrm{~g}$. The animals were anesthetized with urethane $(1.25 \mathrm{~g} / \mathrm{kg}$. i.p.). Polyethylene catheters were inserted into the femoral artery and vein for continuous measurement of blood pressure and for administration of drugs. After tracheotomy, the animals were paralyzed with intravenous infusion of 6.19$8 \mathrm{mg} / \mathrm{kg}$ pancuronium bromide and were ventilated using a respirator. The CBF was measured by the hydrogen clearance method. Briefly, an epoxy-coated platinum electrode. $300 \mu \mathrm{m}$ in diameter, with a $1 \mathrm{~mm}$ portion at its tip uncoated and plated with platinum black, was placed stereotaxically in the striatum and another one in the hippocampus. The reference electrode was an $\mathrm{Ag}-\mathrm{AgCl}$ electrode inserted under the skin. The rectal temperature of animals was maintained close to $37^{\circ} \mathrm{C}$.

As shown in Fig. 1, administration of LDOPS ( $3 \mathrm{mg} / \mathrm{kg}$, i.v.) produced a statistically significant increase in striatal blood flow as well as an elevation in mean arterial blood pressure (MABP), whereas $1 \mathrm{mg} / \mathrm{kg}$ of $\mathrm{L}$ DOPS produced no significant effect on CBF. These effects were long-acting. Similar results were also observed in the hippocampus, but the flow increment was somewhat less than that in the striatum (not shown in the figure). The increases in CBF and MABP produced by L-DOPS were inhibited by about 85 and $70 \%$, respectively. by i.v. infusion of a peripheral aromatic L- 


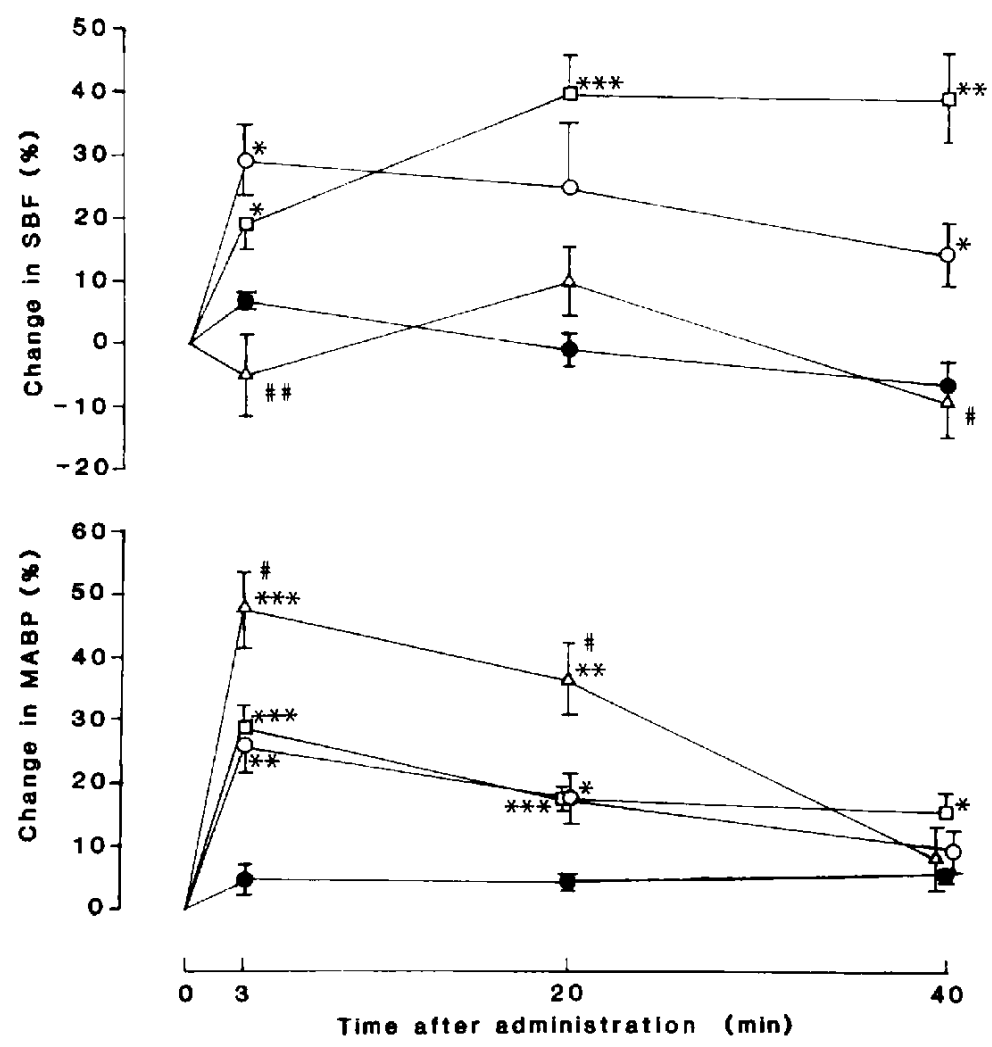

Fig. 1. Effects of intravenously administered L-threo-DOPS and infused norepinephrine on striatal blood flow (SBF) and mean arterial blood pressure (MABP) in anesthetized rats. Each point represents the mean \pm S.E. of four to six animals. Responses are expressed in percent changes as compared with the pre-values. 0 is before the administration. O- Saline. $O-O$ : L-threo-DOPS, $3 \mathrm{mg} / \mathrm{kg} . \mathrm{i} . \mathrm{v}$. $\Delta-\Delta$ : L-threo-DOPS. $3 \mathrm{mg} / \mathrm{kg}$, i.v. plus propranolol, $3 \mathrm{mg} / \mathrm{kg}$. i.p. $\square-\square$ : Norepinephrine, i.v. infusion $(100 \mu \mathrm{g} / \mathrm{kg} / \mathrm{hour}) .{ }^{*} \mathrm{P}<0.05,{ }^{* *} \mathrm{P}<0.01,{ }^{* *} \mathrm{P}<0.001$ : Significantly different from saline. \#P<0.05, \#\#P<0.01: Significantly different from L-threo-DOPS.

amino acid decarboxylase inhibitor, benserazide $(3 \mathrm{mg} / \mathrm{kg} / \mathrm{hr}$ ), prior to the administration of L-DOPS (not shown in the figure). This experimental result suggests that the L-DOPS-induced increase in CBF and MABP is the result of its conversion to NE. $N E$ was also examined in order to compare its action with that of L-DOPS. As shown in Fig. 1. continuous i.v. infusion of NE (100 $\mu \mathrm{g} / \mathrm{kg} / \mathrm{hr}$ ) which raised MABP to the same extent as L-DOPS, exhibited a marked increase in CBF as well. Some lag time was observed, however, in the CBF response to NE before reaching the maximum response in contrast to the instantaneous rise of CBF due to L-DOPS. The difference in the CBF response between L-DOPS and NE may be related to the difference in the distribution between the bioformed NE from L-DOPS and the infused exogenous NE.

The direct action of NE on the cerebrovascular smooth muscle is known to be a constriction. as has been demonstrated in vitro (13) and by microapplication in vivo (14). The literature describing the cerebrovascular action of systemically administered $N E$, however, has been a controversial one (15, 16). Thus, the effect of the injection of NE has in some reports been to decrease the flow, to have no effects, or in others to induce an increase in the CBF. In our present experiments with urethane-anesthetized rats, the i.v. infusion of NE produced an obvious increase in CBF. 
it has been reported that isoprenaline, a $\beta$ adrenoceptor stimulant, markedly increased CBF in rats and that the response was reduced by propranolol, a $\beta$-adrenoceptor antagonist, suggesting that the increase in CBF would be associated with the stimulation of $\beta$-receptor (17). Therefore, we have investigated whether the effects of $L$-DOPS were affected by pretreatment with propranolol or not. The CBF response to L-DOPS was blocked by propranolol ( $3 \mathrm{mg} / \mathrm{kg}$, i.p.). but the MABP response was conversely enhanced by it as shown in Fig. 1. These findings indicate, at least, that the increase in CBF induced by L-DOPS is not the result of the elevation of MABP. Further studies are needed to define the mechanism for the CBF response to L-DOPS or NE in this model, but several possible explanations might be considered such as secondary effects following the increase of cardiac output (6) or $\beta$ receptor mediated direct actions on the cerebrovascular system.

\section{References}

1 Inagaki, C. and Tanaka, C.: Characteristics of enzymic decarboxylation of L-threo-3.4-dihydroxyphenylserine using hog renal $L$-aromatic amino acid decarboxylase. Biochem. Pharmacol. 27, 1081-1086 (1978)

2 Bartholini, G., Constantinidis, J., Puig, M., Tissot, R. and Pletscher, A.: The stereoisomers of 3.4-dihydroxyphenylserine as precursors of norepinephrine. J. Pharmacol. Exp. Ther. 193, 523$532(1975)$

3 Suzuki, T., Higa, S., Sakada, S., Ueji, M., Hayashi, A., Takabe, T. and Nakajima, A.: Pharmacokinetic studies of oral L-threo-3,4-dihydroxyphenylserine in normal subjects and patients with familial amyloid polyneuropathy. Eur. J. Clin. Pharmacol. 23, 463-468 (1982)

4 Kato, T., Katsuyama, M., Karai, N., Hirose, A., Nakamura, M. and Katsube, J.: Reversal of the reserpine-induced ptosis by $L$-threo-3,4dihydroxy-phenylserine (L-threo-DOPS), a (-)norepinephrine precursor, and its potentiation by imipramine or nialamide. Naunyn Schmiedebergs Arch. Pharmacol. 332, 243-246 (1986)

5 Araki, H., Cheng. J.T., Ohmura, I. and Tanaka, C.: Positive chronotropic effect of threo-3,4 dihydroxyphenylserine as a precursor of noradrenaline in rat isolated atria. J. Pharm. Pharmacol. 30, 456-458 (1978)
6 Nakahara, H., Matsui, K. and Hara, Y.: Evaluation of hemodynamic change induced by catecholamines and their precursors in open-chest rats. Japan. J. Pharmacol. 40. Supp. 175P (1986)

7 Araki, H., Tanaka, C., Fujiwara, H., Nakamura, $M$. and Ohmura, I.: Pressor effect of L-threo-3.4dihydroxyphenylserine in rats. J. Pharm. Pharmacol. 33, 772-777 (1981)

8 Katsube, J., Kato, T., Katsuyama, M., Maeda, Y., Nishikawa, S. and Nakamura, M.: Diuretic effect of L-threo-3,4-dihydroxyphenylserine, a norepinephrine precursor, in rats and mice. $J$. Pharm. Pharmacol. 38, 533-544 (1986)

9 Birkmayer, W., Birkmayer, G., Lechner, H. and Riederer, P.: D,L-3,4-threo-DOPS in parkinson's disease: effects on orthostatic hypotension and dizziness. J. Neural Transm. 58, 305-313 (1983)

10 Suzuki, T., Tsuge, 1., Higa, S. and Hayashi, A.: Effect of infused $L$-threo-dihydroxyphenylserine on adrenergic activity in patients with familial amyloid polyneuropathy. Eur. J. Clin. Pharmacol. 17, 429-435 (1980)

11 Kondo, T., Nakazato, T., Takubo, H. and Narabayashi, H.: L-threo-DOPS therapy for the patients with Shy-Drager syndrome. Proceedings of VIil International Symposium on Parkinson's Disease, New York, p. 100 (1985)

12 Narabayashi, H., Kondo, T., Hayashi, A., Suzuki, T. and Nagatsu, T.: L-threo-3,4-Dihydroxyphenylserine treatment for akinesia and freezing of parkinsonism. Proc. Japan. Acad. 57, 351354 (1981)

13 Edvinsson, L. and Owman, C.H.: Pharmacological characterization of adrenergic alpha and beta receptors mediating vasomotor response of cerebral arteries in vitro. Circ. Res. 35, 835-849 (1974)

14 Wahl, M., Kuschinsky, W., Bosse, O., Olesen, J., Lassen, N.A., Ingvar, D.H., Michaelis, J. and Thurau, K.: Effect of I-norepinephrine on the diameter of pial arterioles and arteries in the cat. Circ. Res. 31, 248-256 (1972)

15 Edvinsson, L. and Mackenzie, E.T.: Amine mechanism in the cerebral circulation. Pharmacol. Rev. 28, 275-348 (1976)

16 Kuschinsky, W. and Wahl, M.: Local chemical and neurogenic regulation of cerebral vascular resistance. Physiol. Rev. 58, 656-689 (1978)

17 Edvinsson, L., Locombe, P., Owman, C.H., Reynier-Rebuffel, A.-M. and Seylag, J.: Quantitative changes in regional cerebral blood flow of rats induced by alpha- and beta-adrenergic stimulants. Acta Physiol. Scand. 107, 289-296 (1979) 